\title{
Harvendusraietel toimunud metsaõigusnormide rikkumise juhtumite hindamine
}

\author{
Henn Korjus $^{1 *}$, Mihkel Mets ${ }^{2}$ ja Ahto Kangur ${ }^{1}$
}

Korjus, H., Mets, M., Kangur A. 2020. Revisiting the actual cases of violations of forest management regulations on thinning. - Forestry Studies | Metsanduslikud Uurimused 73, 145-151, ISSN 1406-9954. Journal homepage: http:/ / mi.emu.ee/forestry.studies

\begin{abstract}
Three cases of violation of forest management regulations in Estonia in 2004, 2005 and 2007 are presented in the study where the required lower limit of basal area after thinnings was not followed. These stands were revisited in 2017 to assess the impacts of such thinnings. The actual thinnings were well justified from the silvicultural and economic viewpoints. All three stands were ecologically in good condition in 2017. Also, all three stands had already reached the required age or dimensions allowing regeneration cutting in 2017. Forest management regulations on thinning did not work well in the studied cases and therefore some changes in the current regulations are necessary in Estonia.
\end{abstract}

Key words: thinning regulation, minimum basal area, forestry legislation.

Authors' addresses: ${ }^{1}$ Institute of Forestry and Rural Engineering, Estonian University of Life Sciences, Kreutzwaldi 5, 51014 Tartu, Estonia; ${ }^{2}$ AS Palmako, Kavastu, Luunja vald, 62202 Tartumaa, Estonia; *e-mail: henn.korjus@emu.ee

\section{Sissejuhatus}

Harvendusraietega parandatakse puistusse allesjäävate puude kasvutingimusi puudevahelise konkurentsi reguleerimise teel (Gadow, 1996). Harvendusraiete abil saab mõjutada puistu tervislikku seisundit ning vähendada puude suremust, mis toimuks muidu looduslikult puistu isehõrenemise teel, ning samuti on võimalik puistust tulevikus väljalangevate puude puitu kasutada väärtusliku puidutoodanguna (Tullus, 2002). Harvendusraiete läbiviimiseks on erinevaid võimalusi, mille määravad peamiselt konkreetse puistu seisund (Eriksson, 2006), asukoht, kehtivad seadused ja metsaomaniku eesmärgid (Eastaugh et al., 2013).
Harvendusraiete arvutuslik kavandamine põhineb puistu seisundi analüüsimisel eelkõige puudevahelise konkurentsi aspektist (Pretzsch, 2009). Tihtipeale on harvendusraiet kirjeldavad seosed tunnetusliku iseloomuga ning neil puudub selgelt väljendatud põhjendus (Fenton, 1976). Igas riigis on välja kujunenud oma metsanduslikud traditsioonid ja arusaamine harvendusraiete tegemise kohta (Rio et al., 2017). Selle tõttu on normatiivid sisuliselt erinevad (Mäkinen \& Isomäki, 2004), kuid normatiivid peaksid põhinema teadustöödel ning kogutud andmestikel (Pach et al., 2018). Liiga piiravate nõudmiste korral võib normatiiv takistada metsade majandamist või ei ole sobiv metsaomaniku eesmärkide saavutamiseks oma metsade majandamisel. 
Eestis on metsaomanike võimalused harvendusraiete tegemisel suures ulatuses piiratud. Otsused, mida metsaomanik võib-olla tahaks teha, ei saa metsa majandamise vaatepunktist olla eelduslikult "halvad“. Eestis on täpselt reguleeritud, millise rinnaspindala piirini võib harvendusraiel puistu raiuda. Normatiiv ei arvesta sel puhul puistu struktuuri ega iseärasustega. Samas ei ole võimalik tõenduspõhiselt väita, et kui raiuda puistu allapoole lubatud rinnaspindala normi, vähendab see automaatselt puistu produktiivsust või tekitab otsest kahju looduskeskkonnale.

Selles artiklis vaadeldakse harvendusraietel toimunud üleraiena käsitletud juhtumeid ja arutletakse metsa majandamise eeskirjas (2006) esitatud harvendusraiete järel lubatud rinnaspindala minimaalsete piirmäärade kasutatavuse üle praeguse aja kontekstis. Uurimus põhineb Mihkel Metsa (2017) magistritöös käsitletud kolmel juhtumil.

\section{Materjal ja metoodika}

Harvendusraie normatiivides esitatud raiejärgse seisundi uurimiseks sobivate objektide leidmiseks esitati Keskkonnainspektsioonile päring, mille sisu ja kriteeriumid on järgnevad: soovitavalt aastatel 2000-2010 esinenud metsaõigusnormide rikkumise juhtumid, kus on harvendusraie käigus tekitatud keskkonnakahju puistu liigse harvendamise tõttu, puistu enamuspuuliigiks on mänd või kask või on tegemist lehtpuu enamusega segametsaga, puistu vanus harvendusraie ajal männikutes on 35-55 aastat ning kaasikutes ja segametsades 20-45 aastat ning puistu rinnaspindala raie järel $65-90 \%$ harvendusraiejärgsest lubatud rinnaspindala miinimummäärast.

Andmepäring saadeti Keskkonnainspektsiooni 16. märtsil 2017. a, millele tuli vastus 27. märtsil 2017. a. Päringu tulemuseks oli 16 juhtumit, mis kõik pärinesid Võrumaalt. Juhtumite looduses ülevaatamisel kasutati Deskis OÜ tarkvara
Metsakorraldus, millesse sisestati puistute asukohainfo ja varasemad mõõtmised, et kontrollida puistu seisundit ning puistule ligipääsemise võimalusi. Paljud juhtumid ei sobinud selles töös kasutamiseks, sest puistu rinnaspindala oli harvendusraiega viidud liiga madalale ning juhtumi aluseks olnud puistu oli lagunenud või hiljem metsapatoloogi otsuse alusel uuendatud. Pärast päringus olnud toimikute uurimist valiti välitöödeks välja viis eraldist, millest kaks olid kaasikud ja kolm männikud. Välitööde käigus selgus, et ühes männikus ja ühes kaasikus oli vahepeal tehtud lageraie, seega jäi analüüsimiseks kokku kolm juhtumit. Tabelis 1 on esitatud analüüsimiseks kasutatud juhtumite üldandmed.

Juhtumi 1 puhul on tegemist rahvuspargi piiranguvööndis oleva kaasikuga. Juhtumi 1 puhul oli tõenäoliselt probleemiks teise rinde märkimisväärne esindatus puistus enne raiet metsamajandamiskavas toodud takseerandmete järgi (1. rinde rinnaspindala $16,7 \mathrm{~m}^{2} \mathrm{ha}^{-1}$ ja 2 . rinde rinnaspindala $8,3 \mathrm{~m}^{2} \mathrm{ha}^{-1}$ ). Tõenäoliselt oli takseerandmetes 1 . rinde rinnaspindala alla hinnatud ja tegelik 1 . rinde rinnaspindala ligikaudu $19 \mathrm{~m}^{2} \mathrm{ha}^{-1}$. Lubatud raiejärgne minimaalne 1. rinde rinnaspindala oli 21,9 $\mathrm{m}^{2} \mathrm{ha}^{-1}$ ja tegelik $17,0 \mathrm{~m}^{2} \mathrm{ha}^{-1}$. Harvendusraie käigus säilitati suures osas 2 . rinne. Seega puistus ei olnud harvendusraie lubatud juba enne raie toimumist, harvendusraiel raiuti puistu 1. rinde rinnaspindala $22 \%$ allapoole normatiiviga kehtestatut.

Juhtumi 2 puhul on tegemist üherindelise männikuga, mille 1 . rinde rinnaspindala oli enne raiet $26,4 \mathrm{~m}^{2} \mathrm{ha}^{-1}$ ja pärast raiet $17,8 \mathrm{~m}^{2} \mathrm{ha}^{-1}$. Lubatud raiejärgne minimaalne 1 . rinde rinnaspindala oli $21,3 \mathrm{~m}^{2} \mathrm{ha}^{-1}$, seega harvendusraiel raiuti puistu rinnaspindala $16 \%$ allapoole normatiivi järgi lubatud piirmäära. Juhtumi 2 puhul tekkis kahtlus, et pärast juhtumis fikseeritud harvendusraiet on omanik teinud veel ühe harvendusraie, kuna 2017. aasta hindamise hetkel oli puistu 1. rinde rinnaspindala $15,0 \mathrm{~m}^{2} \mathrm{ha}^{-1}$, mis tegi juhtumi hindamise mõnevõrra keerulisemaks. 
Juhtumi 3 puhul on tegemist üherindelise männikuga, mille rinnaspindala enne raiet oli $16,4 \mathrm{~m}^{2} \mathrm{ha}^{-1}$ ja pärast raiet $10,6 \mathrm{~m}^{2} \mathrm{ha}^{-1}$. Lubatud raiejärgne minimaalne 1 . rinde rinnaspindala oli $20,7 \mathrm{~m}^{2} \mathrm{ha}^{-1}$, seega puistus ei olnud harvendusraie lubatud juba enne raie toimumist ning har- vendusraiel raiuti puistu rinnaspindala $49 \%$ allapoole normatiiviga kehtestatud piirmäära.

Harvendusraietel kasutatud raiekraadiks oli juhtumi 1 puhul 10\%, juhtumi 2 puhul 33\% ja juhtumi 3 puhul 35\%.

Tabel 1. Uuritud harvendusraie juhtumites olevate puistute üldandmed.

\begin{tabular}{llccl}
\hline Juhtum & Asukoht & Pindala ha & Boniteet & Kasvukohatüüp \\
\hline 1 & Võrumaa, Antsla vald & 0,7 & $1 \mathrm{~A}$ & Jänesekapsa \\
2 & Võrumaa, Setomaa vald & 1,9 & 2 & Pohla \\
3 & Võrumaa, Setomaa vald & 3,6 & 3 & Pohla \\
\hline
\end{tabular}

Puistuelementide kõrguse, diameetri ja tagavara prognoosimiseks kasutati Kiviste $(1997,1999)$ diferentsmudelit. Seejuures prognoositi puistuelementide takseertunnused puistu raie-eelsest seisundist lähtudes 2017. aastasse juhul, kui puistus harvendusraiet ei oleks toimunud. Samuti prognoositi tagasiulatuvalt puistu harvendusraiejärgsed takseertunnused 2017. a seisundist lähtudes, et saada harvendusraiel raiutud puude andmed. Kasvava metsa turuväärtuse ja harvendusraiega saadud netotulu hindamiseks kasutati puidusortimentide mahtude arvutamist puistuelementide tagavarast Padari et al. (2009) mudeli põhjal, keskmisi puidusortimentide hindasid 2017. a detsembris (Hepner, 2017) ja keskmist raietööde ja puidu transpordi koguhinda $17 € / \mathrm{m}^{3}$. Metsa uuendamisest saadav lisatulu on arvutatud lähtuvalt järgmise raieringi ajalisest nihkest aastates ja puistu keskmisest rahalisest tootlikkusest. Harvendusraie rahalise tasuvuse hinnangus on lähtutud vaid metsamajanduslikust aspektist ega arvestata sellega, et toimus oigusnormi rikkumine, millega kaasnesid trahvid ja/või muud rahalised nõuded.

\section{Tulemused}

Tabelis 2 on esitatud juhtumites käsitletud puistute takseerandmed enne harvendusraiet ja tehtud välimõõtmiste tulemusel
2017. a. Kordusmõõtmistel saadud andmed näitavad, et juhtumite 1 ja 3 korral on puistus pärast harvendusraiet rinnaspindala ja tagavara märkimisväärselt suurenenud. Juhtumite 2 ja 3 puhul on saavutatud puistutes elujõuline ja väärtuslik järelkasv. Visuaalsete vaatluste ning kordusmõõtmiste andmete analüüsi tulemusena ei selgu, et puistutes oleks harvendusraietel tehtud midagi looduskaitse või metsakasvatuse seisukohalt valesti. Juhtumid 1 ja 3 nägid välja nagu tavalised puistud, kus on tehtud harvendusraiet. Kõigi kolme juhtumi puhul on 2017. aastaks saavutatud puistud, kus uuendusraie on lubatud.

Harvendusraie rahalise tasuvuse hinnang on esitatud tabelis 3 . Reaalsed juhtumid osutusid metsaomaniku seisukohast kasulikumaks, võrreldes olukorraga, kui nad harvendusraiet ei oleks teinud. Oluline osa lisatulu tekkimises oli juhtumite 2 ja 3 puhul elujõulise metsauuenduse saavutamine, mis võimaldab järgmise puistu kasvatamise aega lühendada 10-15 aasta võrra.

\section{Arutelu}

Normatiivid kehtestatakse metsade majandamisel selleks, et määratleda või piiritleda teatud tegevusi kõikidele osapooltele üheselt mõistetavaks ja kasutatavaks. Probleem tekib siis, kui normatiivid kujunevad liiga piiravaks või ei ole mõistlikult põhjenda- 
Tabel 2. Uuritud juhtumites puistute takseerandmed metsamajandamiskavade andmetel enne harvendusraiet ja välitööde andmetel 2017. a.

\begin{tabular}{|c|c|c|c|c|c|c|c|c|}
\hline Juhtum & Aasta & Puuliik & Rinne & $\begin{array}{l}\text { Diameeter } \\
(\mathrm{cm})\end{array}$ & $\begin{array}{c}\text { Kõrgus } \\
\text { (m) }\end{array}$ & Vanus (a) & $\begin{array}{l}\text { Tagavara } \\
\left(\mathrm{m}^{3} \mathrm{ha}^{-1}\right)\end{array}$ & $\begin{array}{l}\text { Tihedus } \\
\left(\mathrm{tk} \mathrm{ha}^{-1}\right)\end{array}$ \\
\hline \multirow[t]{6}{*}{1} & & KS & 1 & 24 & 25 & 55 & 206 & \\
\hline & \multirow[t]{3}{*}{2005} & MA & 1 & 22 & 24 & 60 & 15 & \\
\hline & & $\mathrm{KU}$ & 2 & 16 & 17 & 40 & 86 & \\
\hline & & KS & 1 & 26 & 26 & 67 & 225 & \\
\hline & \multirow[t]{2}{*}{2017} & MA & 1 & 24 & 26 & 72 & 44 & \\
\hline & & $\mathrm{KU}$ & 2 & 22 & 20 & 52 & 155 & \\
\hline \multirow[t]{5}{*}{2} & 2004 & MA & 1 & 22 & 22 & 68 & 261 & \\
\hline & \multirow{4}{*}{2017} & MA & 1 & 28 & 23 & 81 & 160 & \\
\hline & & MA & $\mathrm{J}$ & 1 & 2 & 10 & & 7000 \\
\hline & & KS & $\mathrm{J}$ & 2 & 4 & 10 & & 1000 \\
\hline & & $\mathrm{HB}$ & $\mathrm{J}$ & 2 & 4 & 10 & & 1000 \\
\hline \multirow[t]{3}{*}{3} & 2007 & MA & 1 & 22 & 19 & 90 & 235 & \\
\hline & \multirow{2}{*}{2017} & MA & 1 & 26 & 22 & 100 & 196 & \\
\hline & & MA & $\mathrm{J}$ & 1 & 2 & 6 & & 5000 \\
\hline
\end{tabular}

Tabel 3. Uuritud juhtumites kasvava metsa väärtuse ja metsamajanduslike tegevuste rahaline hinnang nii harvendusraie tegemisel kui ka tegemata jätmisel.

\begin{tabular}{|c|c|c|c|c|}
\hline $\mathrm{Nr}$ & Kirjeldus & Juhtum 1 & Juhtum 2 & Juhtum 3 \\
\hline \multicolumn{5}{|c|}{ 1. Reaalne juhtum, kus metsaomanik tegi harvendusraie. } \\
\hline & $\begin{array}{l}\text { Eraldisel kasvava metsa rahaline väärtus 2017. a, } \\
\text { eurodes }\end{array}$ & 9692 & 15052 & 33810 \\
\hline & $\begin{array}{l}\text { Eraldisel tehtud harvendusraiega saadud netotulu, } \\
\text { eurodes }\end{array}$ & 761 & 7077 & 11742 \\
\hline & $\begin{array}{l}\text { Metsa varasema uuendamisega seoses saadav } \\
\text { lisatulu tulevikus, eurodes }\end{array}$ & 0 & 3566 & 3791 \\
\hline & Metsa ja tegevuste koguväärtus kokku, eurodes & 10453 & 25695 & 49343 \\
\hline \multicolumn{5}{|c|}{ 2. Juhul, kui metsaomanik oleks jätnud harvendusraie tegemata. } \\
\hline & $\begin{array}{l}\text { Eraldisel kasvava metsa rahaline väärtus kokku } \\
\text { 2017. a, eurodes }\end{array}$ & 8280 & 24687 & 37905 \\
\hline
\end{tabular}

tud. Harvendusraied annavad metsaomanikule võimaluse kasutada puudevahelises konkurentsis väljalangevate puude puitu ja kujundada puistu, mis võimaldab uuendusraiel saada väärtuslikumad puidusortimendid. Metsa majandamise eeskirjas (2006) on harvendusraied normeeritud raiejärgse minimaalse lubatava 1 . rinde rinnaspindala järgi lähtuvalt puistu 1. rinde enamuspuuliigist ja puistu vastavast kõrgusest. Juhtu- mi 1 puhul oli suure tõenäosusega tegemist kunagise vähehooldatud kuusekultuuriga, millest kased olid üle kasvanud. Seetõttu oli kuuse puistuelement teises rindes ja seda ei võetud rinnaspindala normatiivi vastavuse hindamisel arvesse. Samas puistu majandamise seisukohalt oli oluline kased osaliselt välja raiuda, et anda kuuskedele kasvuruumi lisaks. Puistu seisund oli 12 aastat pärast harvendusraiet hea ja tehtud harvendusraie 
oli metsakasvatuslikult kindlasti õigeaegne ja põhjendatud.

Tulundusmetsade majandamisel on metsaomandi ja puistute tasemel üks oluline eesmärk saavutada rohkem tulu (Korjus et al., 2011; Kaimre et al., 2020). Harvendusraietega saab puistute küpsusvanust vähendada 10-20 aastat (Fenton, 1976; Mathiesen, 1997). Juhtumite 2 ja 3 puhul saavutati puistute elujõuline looduslik uuendamine vähemalt 10-13 aastat varem kui ilma harvendusraieta, samas eraldiselt saadav rahaline tulem suurenes (juhtum 3) või oluliselt ei vähenenud (juhtum 2). Selle poolest sarnanesid juhtumites 2 ja 3 tehtud harvendusraied varem kasutusel olnud põimendusraiete põhimõtetele.

Siinses uurimuses kasutatud metsaõigusnormide rikkumise kolme juhtumi puhul selgus puistute kordusmõõtmistel, et harvendusraietega ei tehtud tegelikult olulist kahju looduskeskkonnale ega puistute toodanguvõimele. Metsaomanike tegutsemisele ei tohiks ette seada põhjendamata institutsionaalseid takistusi (Põllumäe et al., 2016), pigem tuleks riigil soovitud tegevuste saavutamiseks rakendada mitmesuguseid erametsanduse toetusskeeme (Põllumäe et al., 2019). Selle uurimuse tulemus tõstatab kahtluse, kas kehtivad harvendusraie normatiivid on praktikas rakendamiseks selgelt teaduslikult põhjendatud alustel ning kas nad on omandi pikaajalise majandamise seisukohast majanduslikult mõistlikud. Tavapärasest hõredamates puistutes väheneb puudevaheline konkurents ja seetõttu toimub aktiivsem puude diameetri juurdekasv (Mäkinen \& Isomäki, 2004; Maleki et al., 2015). Juba algusest peale hõredana majandatud puistud võivad olla mitmesuguste riskitegurite suhtes märksa vastupidavamad (Roessiger et al., 2013) kui tihedad vähehooldatud kultuurpuistud. Seetõttu tuleks kehtivad harvendusraiete normatiivid üle vaadata ja otsustada, kui suurel määral on vajalik puistute raiejärgset seisundit reglementeerida.

\section{Kasutatud kirjandus}

Eastaugh, C.S., Kangur, A., Korjus, H., Kiviste, A., Zlatanov, T., Velichkov, I., Srdjevic, B., Srdjevic, Z., Hasenauer, H. 2013. Scaling issues and constraints in modelling of forest ecosystems: A review with special focus on user needs. - Baltic Forestry, 19(2), 316-330.

Eriksson, E. 2006. Thinning operations and their impact on biomass production in stands of Norway spruce and Scots pine. - Biomass and Bioenergy, 30, 848-854. https://doi. org/10.1016/j.biombioe.2006.04.001.

Fenton, R. 1976. The economics of thinning. - New Zealand Journal of Forestry Science, 6, 273-282.

Gadow, K. v. 1996. Modelling growth in managed forests - realism and limits of lumping. - Science of The Total Environment, 183, 167-177. https://doi.org/10.1016/00489697(95)04979-7.

Hepner, H. 2017. Overwiev of Roundwood Market in Q4, 2017. (Ülevaade 2017. aasta IV kvartali puiduturust). Kohila, OÜ Tark Mets. 16 pp.

Kaimre, P., Vellak, P., Teder, M. 2020. Economic analysisand simulation of theimpact of thinning on wood production in Järvselja Training and Experimental Forest Centre. - Forestry Studies / Metsanduslikud Uurimused, 72, 54-63. https://doi.org/10.2478/fsmu-2020-0005. (In Estonian with English summary).

Kiviste, A. 1997. An algebraic difference model for the forest growth simulation in Estonia. (Eesti riigimetsa puistute kõrguse, diameetri ja tagavara vanuseridade diferentsmudel 1984.1993. a. metsakorralduse takseerkirjelduste andmeil). - EPMÜ teadustööde kogumik, 189, 63-75. (In Estonian).

Kiviste, A. 1999. About the Estonian forest growth models. (Eesti puistute kasvumudelitest). EPMÜ metsandusteaduskonna toimetised, 28-36. (In Estonian).

Korjus, H., Põllumäe, P., Rool, S. 2011. Profitability analysis of short rotations in Scots pine, Norway spruce and silver birch stands. - Forestry Studies / Metsanduslikud Uurimused, 54, 2836. https:/ / doi.org/10.2478/v10132-011-00937. (In Estonian with English summary).

Maleki, K., Kiviste, A., Korjus, H. 2015. Analysis of individual tree competition effect on diameter growth of silver birch in Estonia. - Forest Systems, 24(2), e023. https:/ / doi.org/10.5424/ fs / 2015242-05742.

Mathiesen, A. 1997. Forest Management Planning. (Metsakorraldus). Tartu, Eesti PõllumajandusülikooliMetsandusteaduskond. 195 pp. (In Estonian).

Mets, M. 2017. Analysis of minimum basal area requirement on thinnings. - Master's Thesis. Tartu, Estonian University of Life Sciences. 47 pp. (In Estonian with English summary).

Metsa majandamise eeskiri. 2006. Forest management regulation. (Metsa majandamise eeskiri). - RT I, 15.12.2017, 17. (In Estonian). 
Mäkinen, H., Isomäki, A. 2004. Thinning intensity and growth of Scots pine stands in Finland. Forest Ecology and Management, 201, 311-325. https:/ / doi.org/10.1016/j.foreco.2004.07.016.

Pach, M., Sansone, D., Ponette, Q., Barreiro, S., Mason, B., Bravo-Oviedo, Andres, Löf, M., Bravo, F., Pretzsch, H., Lesiński, J., Ammer, C., Đodan, M., Peric, S., Bielak, K., Brazaitis, G., del Río, M., Dezzotti, A., Drössler, L., Fabrika, M., Fonseca, T., Govedar, Z., Kangur, A., Kurylyak, V., Loguercio, G.A., LibieteZalite, Z., Madsen, P., Matović, B., Meliadis, I., Meliadis, M., Metslaid, M., Mounir, F., Müller-Using, S., Short, I., Souidi, Z., Sterba, H., Stojanović, D., Svoboda, M., Verheyen, K., Yildiz, O., Zahvoyska, L., Zlatanov, T., Corona, P. 2018. Silviculture of mixed forests: A European overview of current practices and challenges. - Bravo-Oviedo, A., Pretzsch, H., del Río, M. (eds.). Dynamics, Silviculture and Management of Mixed Forests. Cham, Springer International Publishing, 185-253. https:/ / doi.org/10.1007/978-3-319-91953-9_6.

Padari, A., Muiste, P., Mitt, R., Pärn, L. 2009. Estimation of Estonian wood fuel resources. Baltic Forestry, 15, 77-85.

Põllumäe, P., Lilleleht, A., Korjus, H. 2016. Institutional barriers in forest owners' cooperation: The case of Estonia. - Forest Policy and Economics, 65, 9-16. https://doi. org/10.1016/j.forpol.2016.01.005.
Põllumäe, P., Lilleleht, A., Korjus, H. 2019. Reflections of active forest owners to the public-private forestry support system in Estonia. - Forestry Studies / Metsanduslikud Uurimused, 71, 100-119. https://doi. org/10.2478/fsmu-2019-0015.

Pretzsch, H. 2009. Standard analysis of longterm experimental plots. - Pretzsch, H. (ed.). Forest Dynamics, Growth and Yield: From Measurement to Model. Berlin, Heidelberg, Springer, 181-222. https://doi. org/10.1007/978-3-540-88307-4_6.

Rio, M., Bravo-Oviedo, A., Pretzsch, H., Löf, M., Ruiz-Peinado, R. 2017. A review of thinning effects on Scots pine stands: From growth and yield to new challenges under global change. - Forest Systems, 26, eR03S. https://doi. org/10.5424/fs/2017262-11325.

Roessiger, J., Griess, V.C., Härtl, F., Clasen, C., Knoke, T. 2013. How economic performance of a stand increases due to decreased failure risk associated with the admixing of species. Ecological Modelling, 255, 58-69. https:/ / doi. org/10.1016/j.ecolmodel.2013.01.019.

Tullus, H. 2002. The influence of intermediate cuttings on the growth of pine and spruce forests: silvicultural recommendations. - Forestry Studies / Metsanduslikud Uurimused, 36, 126-135. 


\title{
Revisiting the actual cases of violations of forest management regulations on thinning
}

\author{
Henn Korjus, Mihkel Mets and Ahto Kangur
}

\section{Summary}

Three cases of violation of forestry regulations are presented in this study where the required lower limit of basal area after thinnings was not followed. These recorded actual cases of violations happened in Estonia in 2004, 2005 and 2007. One stand was dominated by silver birch and two stands by Scots pine. The basal area after thinning in these cases was $16-49 \%$ lower than required by regulations. The stands were revisited in 2017 to assess the impacts of the violations. All three stands were found in good ecological condition in 2017. In all these cases, thinning was justified enough from the silvicultural and economical viewpoints. All three stands had reached already the required age or dimensions allowing regeneration cutting in 2017. There should not be scientifically unfounded barriers in forest management, particularly concerning private forestry, and financial subsidies can be used instead of government regulations to promote preferred methods in forest management. Forest management regulations did not work well in the studied cases and therefore some changes in the current regulations on thinnings may be necessary in Estonia. 